\title{
La noción agustiniana de "sacramentum" en la interpretación de J. L. Berti
}

Sacramento se ha trocado en palabra de actualidad y se ha apelado a ella en todos los tonos y bajo diferentes aspectos. La misma Iglesia se ha presentado "como un sacramento o signo e instrumento de la íntima unión con Dios y de la unidad de todo el género humano" - veluti sacramentum seu signum et instrumentum, diría el Concilio Vaticano II- ${ }^{1}$. A pesar de todo no significaba esto, sino la ampliación de un concepto que patrísticamente se había explotado en sentido muy variado.

En la intención de enfocar el tratado sobre los sacramentos, el teólogo agustino Juan Lorenzo Berti ${ }^{2}$ comenzaba por decir que del costado abierto de Cristo habían brotado la Iglesia y los sacramentos ${ }^{3}$. No se planteaba la Iglesia como sacramento primordial, sino que se

1 Const. dogm. Lumen gentium I, 1, que se hacía eco de los múltiples estudios publicados precedentemente sobre el argumento, pero a su vez conservaba en la expresión una justa prudencia y moderación.

2 No necesitamos biografiarlo aquí. Remitimos a J. MoRÁN, "Juan Lorenzo Berti y su interpretación de la "memoria Dei" agustiniana": La Ciudad de Dios 76 (1963) 235-264, donde recogemos algunos estudios. Para una amplia bibliografía, cfr. F. Rojo, "Ensayo bibliográfico de Noris, Bellelli y Berti": Analecta Augustiniana 26 (1963) 294-363, p. 336-353.

3' J. L. BERTI, De theologicis disciplinis. Tomus III in quo agitur De Verbo facto Homine, et de mirabili humanae reparationis Oeconomia; necnon de Sacramentis in genere ac de Baptismo, Romae 1765, 168. Cita aquí In Joan. Evang. tr. 120, 2, PL. 35, 1953: Vigilanti verbo Evangelista usus est, ut non diceret, Latus ejus percussit, aut vulneravit, aut quid aliud; sed, aperuit: ut illic quodammodo vitae ostium panderetur, unde Sacramenta Ecclesiae manaverunt, sine quibus ad vitam quae vera vita est, non intratur. Ille sanguis in remissionem fusus est peccatorum: aqua illa salutare temperat poculum; haec et lavacrum praestat, et potum. Haec praenuntiabat quod Noe in latere arcae ostium facere jussus est (Gen 6,16), qua intrarent animalia quae non erant diluvio peritura, quibus praefigurabatur Ecclesia. Propter hoc prima mulier facta est de latere viri dormientis (Id. 2, 22), et appellata est vita materque vivorum (Id. 3, 20). Magnum quippe significavit bonum, ante magnum praevaricationis malum. Huc secundus Adam inclinato capite in cruce dormivit, ut inde formaretur ei conjux, quod de latere dormientis effluxit. 0 mors unde mortui reviviscunt! Quid isto sanguine mundius? Quid vulnere isto salubrius? Añade otros muchos lugares, entre los que podríamos señalar $E n$. in ps. 40, 10, PL. 36, 461; En. in ps. 56, 11, PL. 36, 668; En. in ps. 65, 7, PL. 36, 793; En. in ps. 138, 2, PL. 37, 1.785; In Joan. Evang. tr. 9, 10, PL. 35, 1.463; De civ. Dei XV, 26, 1, PL. 41, 472. 
asignaba el mismo origen a la Iglesia y a los sacramentos, que procedían del mismo Cristo, siendo $\mathrm{El}$ el autor e institutor de ambas realidades misteriosas que se completaban mutuamente.

La noción de sacramento ofrece en Berti una visión clara. Ello nos ha movido a buscar las raíces profundas de su explicación, conscientes de que estriba en San Agustín. La sacramentaria del Obispo de Hipona ha sido objeto de muchos estudios en nuestro tiempo ${ }^{4}$, y todavía sigue sin dilucidar plenamente. Por este hecho Berti podría aportarnos cierta luz a un esclarecimiento. La diversidad de significados se había puesto de manifiesto en un estudio filológico-doctrinal ${ }^{5}$ y hemos comprobado que el teólogo agustino había ya antes con ojo avizor descubierto esa realidad, si bien no había recorrido todos los textos agustinianos. Hemos tenido forzosamente que limitarnos, ya que algunos temas nos ofrecerían

4 Cfr. P. Foulquie, "Un texte de saint Augustin sur la matière et la forme des sacrements": Recherches de Science Religieuse 17 (1927) 146; C. SPALLANzANI, "La nozione di Sacramento in Sant'Agostino": La Scuola Cattolica 9 (1927) 175-188, 258-268; E. NEVEuT, "La Théologie sacramentaire de saint Augustin": Divus Thomas (Piacenza) 34 (1931) 3-27; M. Gierens, De causalitate sacramentorum seu de modo explicandi efficientiam sacramentorum novae legis textos scholasticorum principaliorum collegit, Romae 1935, 13-15, n. ${ }^{\circ} 1-4$; H. A. van der Mensbrugghe, "The Concept of a sacrement in Non-augustinian Theology": The Christian East 15 (1935) 95-107, publicado también en francés "La notion d'un sacrament en théologie non agustinienne": Oecumenica 3 (1936) 286-296; R. RUSSEL, "The Concept of a sacrement in St. Augustine". (On occasion of a recent article in "The Christian East"): The Eastern Churches Quarterly 1 (1936) 73-79, 121-131; A. L. LILLEY, Sacrements. A Study of some moments in the attempt to define their meaning for christian worship, London 1928, $31-50$; H. M. FÉRET, "Sacramentum-Res dans la langue théologiaue de saint Augustin": Revue des Sciences Philosophioues et Théologiques 29 (1940) 218-263; P. V. KORNYLJAK, Sancti Augustini de efficacitate sacramentorum doctrina contra Donastistas, Romae-Philadelphiae 1953; R. Prenter, "Metanhysics and Eschatology in Sacramental Teaching of St. Augustine": Studia Theologica 1 (1947) 5-26; F. van der MeER, "Sacramentum chez S. Augustin": La MaisonDieu 13 (1948) 50-64; N. M. HARING, "St. Augustine's Use of the Word Character": Medieval Studies 14 (1952) 79-97; Ch. CouTurIER, "Sacramentum et Mysterium dans l'oeuvre de saint Augustin": Etudes Auqustiniennes, París 1953 , 161-332; N. M. HARING, "The Augustinian Axiom: Nulli sacramento injuria facienta est": Medieval Studies 16 (1954) 87-117; J. R. N. NoLAN, The doctrine of Saint Augustine in the sacramental Character. Diss. Roma 1956 (dact.); P. T. CAMELOT, "Sacramentum. Notes de théologie sacramentaire augustinienne": Revue Thomiste 57 (1957) 429-449; J. GaILlaRd, "Saint Augustin et les sacrements de la foi. Verbum fidei in Ecclesia Dei": Revue Thomiste 59 (1959) 664-703; L. VILLETTE, Foi et Sacrement I. Du Nouveau Testament à saint Augustin, París 1959, 217-329; B. MoREL. Le signe sacré. Essai sar le sacrement comme signe et information de Dieu, París 1959, 23-37; F. MoRIones, Enchiridion Theologicum Sancti Auqustini, Matriti 1961, 549-564: M. F. BERRouARD, "Similitudo et la définition du réalisme sacramentel d'après l'Epître 98. 9-10 de saint Augustin": Studia Patristica VI/4 edited by F. L. Cross, Berlín 1962, 277-293.

5 Ch. Couturier, "Sacramentum et Mysterium dans l'oeuvre de saint Augustin": Études Augustiniennes, París 1953, 161-332. 
material abundante para un artículo amplio, como por ejemplo, el problema de la circuncisión.

Berti en este tema, como en los demás, continúa su método teológico ${ }^{6}$. Este método se manifiesta en toda la escuela agustiniana y es patrimonio común en los autores que la representan ${ }^{q}$. Difícilmente se halla en las diferentes tendencias teológicas que se han sucedido a través de la historia una que se acerque más a lo preconizado en el Concilio Vaticano II para el estudio de la teología ${ }^{8}$. La Escritura, el magisterio de la Iglesia, las tradiciones apostólicas, los Padres, la interpretación filológica fuerte, las aserciones de los teólogos: he aquí los pasos necesarios en los teólogos agustinos. Centran de ordinario el argumento patrístico en San Agustín, viéndole a él como catalizador de los escritores precedentes y como fuente de los siguientes. En la sacramentaria, Berti nos ofrece un ejemplo singular de este hecho. Por esto nos detendremos brevemente en la noción de "sacramentum" y en la interpretación que hace Berti de los textos agustinianos que multiplica a lo largo de sus exposiciones.

\section{MYSTERIUM Y SACRAMENTUM.}

El gran teólogo agustino comienza por anotar que la palabra no es nueva, y que no puede achacarse a la teología católica el que haya

6 Lo expresa con estas significativas palabras en la Introducción al Tom. I de esta obra, dirigiéndose a los alumnos: "Vos saltem, adolescentes optimi, in singulis fidei controversiis expendite priori loco sacras litteras additis Catholicorum interpretationibus, consulite traditiones Apostolicas, exquirite Ecclesiae definitiones, examinate testimonia Patrum, attendite verborum omnium scopum ac sensum, probate communes Theologorum assertiones; atque haec vestra propugnacula sint: non mentis figmenta, non fallaciarum structura, non jejuna, non spinosa ratiocinatio. Pugnantia Scholarum placita versate cum ingenii moderatione; parum vos exerceant Veterum quodlibeta: sive Aristoteles dixerit, sive Plato vera tantum probate; ante interpretum commentaria scrutamini textus Auctorum, saepenumero magis, quam sint aliorum Interpretamenta, perspicuos. Haec vobis monita praescribo; reliqua vos usus atque experimentum docebit" (J. L. BerTi, o. c. I, XXII).

7 Han dejado constancia de ello con referencias bibliográficas D. GuTiérREZ, "Ermites de saint Augustin": Dictionnaire de Spiritualité IV, 990-1.003, 9381.018; ID., "Ascéticos y místicos agustinos de España, Portugal e Hispanoamérica": Sanctus Augustinus vitae spiritualis Magister, II, Roma 1959, 147-238, concretamente p. 224-238; A. TuRRaDo, Espiritualidad agustiniana y vida de perfección. El ideal monástico agustiniano en Santo Tomás de Villanueva, Madrid 1966, 176-186; A. Trapé, "Scuola teologica e spiritualità nell'Ordine Agos . tiniano": Sanctus Augustinus vitae spiritualis Magister, II, Roma 1959, 5-75, si bien aquí en el problema del método entra muy poco. Sobre la escuela teológicoigustiniana puede verse bibliografía en J. MORÁN, a. c. 235 , nota 1.

8 Cfr. Decr. Optatam totius 14 y 16. 
inventado el término, como si debiera evitar todas las novedades de lenguaje ${ }^{9}$. Se encuentra ya en la Escritura el término mysterium, que en su mayor parte se ha traducido por sacramentum, pero luego los Padres han recogido el vocablo y lo han cargado de significaciones, no solamente en conformidad con la Escritura, sino extrayéndolas también de la literatura profana. Entre los Padres ocupa un puesto de honor San Agustín, que ha podido tomar el término de los autores que le precedieron ${ }^{10}$. Los autores clásicos citados por Berti son Tertuliano ${ }^{11}$, San Cipriano ${ }^{12}$, San Hilario ${ }^{13}$ y San Ambrosio ${ }^{14}$. Y dadas las relaciones literarias que Agustín ha mantenido con ellos es muy posible que a ellos haya pedido ayuda a la hora de emplear la palabra sacramentum. El término no es nuevo, es escriturístico y patrístico y en la lengua latina ha traducido el griego mysterion ${ }^{15}$.

La dificultad, como es fácilmente comprensible, no radica en el término usado, sino en las significaciones dadas. Berti camina por pasos y lentamente, sabiendo que la obra la dirige a estudiantes en teología, que necesitan que se les descubran los problemas progresivamente. El término sacramentum unido a mysterium aparece indistintamente en San Agustín, y Couturier ha recogido 2.279 empleos de esas palabras ${ }^{16}$. Su análisis confirma con profusión algunas de las conclusiones que se habían ya extraído de un examen menos exhaustivo de la obra agustiniana.

Significaciones de "sACRAMENTUM".

Una primera constatación se impone a cualquiera que se interne en la sacramentaria de los Padres, pero más todavía si entra en el

9 Para oponerse a esto cita un amplio texto de S. Agustín en el que se apunta que son las novedades profanas las que hay que evitar y no éstas, ya recibidas y conformes a la Escritura, In Joan. Evang. tr. 97, 4, PL. 35, 1.879-1.880, citado por BERTI, o. c. III, 169.

10 Poniendo en relación el texto griego y la traducción de I Cor 13, 2 aduce un pasaje del Contra litt. Petil. II, 77, 172, PL. 43, 311-312, en el que mysterium vendría asimilado a sacramentum, ya que se hace referencia al bautismo. Luego se añaden otros textos en que se emplea el vocablo en ese sentido Epist. 54, 1, 1, PL. 33, 200; Contra F'austum XIX, 13, PL. 42, 355.

11 De bapt. 1, PL. 1, 1.305; 13, col. 1.323; De praescript. haeret. 40, PL. 66.

12 Epist. 63, PL. 4, 384-401; Epist. 77, PL. 4, 427-433.

13. Comment. in Matth. 4, 27, PL. 9, 942; 9, 3, col. 963.

14 Ambrosius - dice nuestro autor, III, 169- de Sacramentis libros sex sacra eruditione plenos conscripsit: Cfr. PL. 16, 435-482.

15 Cf. P. VISENTIN, "Mysterion-Sacramentum" dai Padri alla Scolastica": Studia Patavina 4 (1957) 394-414. Berti ha expuesto todo esto en la p. 169

16 Véase nota 5. 
estudio de la misma en San Agustín: el término se emplea en diferentes sentidos, la significación no es única ${ }^{17}$. Berti reduce esos significados a los siguientes:

a) Suelen llamarse sacramentos los principales puntos de la doctrina eclesiástica que en los primeros siglos de la Iglesia se ocultaban a los gentiles, sea en relación con los dogmas de fe, sea en relación con la eucaristía, o con la consagración de otros misterios, ritos y celebraciones ${ }^{18}$. La ley del arcano y por ende de algo oculto, invisible, que no puede ser descubierto a todos, es un principio de interpretación para lo sacramental. Esto mismo ayudará a la comprensión de una terminología muy común en los Padres de "iniciación a los misterios", existente en los paganos, pero ya cristianizada, como imbuere sacramenta, que significa dejarse penetrar y como impregnar por el misterio mismo ${ }^{19}$.

Este primer significado Berti lo descubre también en San Agustín. Un primer texto es aquel en que Agustín, exponiendo Eph. 3, 14-19 sobre la longitud, la altura y la profundidad, habla de la cruz y asimila los sacramentos a la parte que se oculta bajo la tierra y la mantiene en alto y de la que pende lo que aparece ${ }^{20}$. Y con éste cita otro texto de la Epistola a Honorato, que se titula Sobre la gracia del Nuevo Testamento, en el que se dice que el sacramento grande del sacrificio del Nuevo Testamento lo descubrirá cuando esté bautizado ${ }^{21}$. Se oculta al hombre ordinario y al no bautizado, y solamente cuando reciba el bautismo, se

17 Recordemos solamente la obra conjunta, ya antigua en el tiempo, pero siempre rica en contenido de J. DE GHELlinck - E. DE BACKeR - J. Poukens G. LEBACQz, Pour l'histoire du mot "sacramentum", Louvain 1924; B. MoREL, Le signe sacré. Essai sur le sacrement comme signe et information de Dieu, París 1959. Para San Agustín, véase la nota 4.

18 J. L. BERTI, o. c. III, 170 , pero ha recordado también recurriendo a los autores latinos las significaciones, diríamos, judiciales y militares (p. 16). Hemos preferido limitarnos a aquellos aspectos en que Agustín aparece con más claridad, si bien el matiz militar tendrá en Agustín una importancia capital sin duda en depedencia de Tertuliano y de otros autores latinos. El estudio está todavía abierto.

19 P. Th. Camelot, "Sacramentum fidei": Augustinus Magister II, París 1954, 892.

20 En. in ps. 103, sem. 1, 14, PL. 1.345: Quid est quot occultum est et non publicum in Ecclesia? Sacramentum Baptismi, Sacramentum Eucharistiae. Opera enim nostra vident et Pagani, Sacramenta vero occultantur illis: sed ab his quae non vident, surgunt illa quae vident; sicut a profundo crucis quod in terra figitur, surgit tota crux quae apparet et cernitur.

21 Epist. 140, 19, 48, PL. 33, 558: Omnia largitur, et praescit: sed peccata praedicit, supplicia minatur, beneficia pollicetur. Filii ergo promissionis, filii sunt beneficii. Haec est gratia, quae gratis datur, non meritis operantis, sed miseratione donantis. Hinc gratias agimus Domino Deo nostro, quod est magnum sacramentum in sacrificio novi Testamenti, quod ubi et quando et quomodo offeratur, cum fueris baptizatus, invenies. 
revela el sacramento oculto en el Nuevo Testamento y el sacrificio que se ofrece.

Este punto abre un gran horizonte a la sacramentaria. Ya había sido puesto de relieve por los autores en el estudio sobre el bautismo y la eucaristía en el Santo ${ }^{22}$. Berti interpreta los textos aducidos de este modo también. Lo oculto $-\mathrm{y}$ siempre sacramento, comportará algo de oculto e invisible - es la totalidad, es decir, la parte doctrinal que se desvela poco a poco en la catequesis, en la enseñanza, y la parte carismática, la gracia que se percibía luego. Entonces imbuere sacramenta era inteligencia progresiva e impregnación por el misterio ${ }^{23}$.

b) A este sentido se acerca aquel otro según el cual se usa el término "sacramentum" para designar res arcana. Eso significaría el sacramento en su sentido amplio ${ }^{24}$, y a éste se referirían todos los sentidos simbólicos del Viejo Testamento y cuanto pudiera considerarse bajo el nombre de sacramento-símbolo. Berti no desvela aquí este significado. Lo hace al tratar de exponer hasta qué punto puede hablarse de sacramento en el estado de inocencia, interpretando en este sentido los textos agustinianos. $\mathrm{Y}$ en ello tendría razón ${ }^{25}$. Los términos son empleados allí con esa perspectiva y no en un sentido estricto teológico, que, por otra parte, es difícil de hallar y de concretar en el Santo. Habría una cierta diferencia entre este sentido y el anterior, pero sería de acento, en cuanto que uno estriba en lo docrinal, y el otro en lo simbólico.

c) Sacramento se emplea como signo de una cosa sagrada. La nueva aproximación a la noción de sacramento se centra en San Agustín. A este propósito examina la noción de signo a partir del De doctrina christiana I, 2, 2, PL. 34, 19-20, y luego añade la definición más precisa conocida de todos ${ }^{26}$. Con esos supuestos agrega que no puede llamarse sacramento

\footnotetext{
nota 4

Cf. P. Th. Camelot, Spiritualité du Baptême, París 1960, vid. también

23 Puede verse un resumen de estas ideas en $P$. Th. Camelot, "Sacramentum fidei": Augustinus Magister II, París 1954, 893-894.

24 BERTI, o. c. III, 173, interpretando algunos textos del De Gen. ad litt., como se verá más adelante.

25 Ch. Couturier (a. c. 189-255) ha insistido sobre todo en el sacramentosímbolo, estudiando principalmente los símbolos del Antiguo Testamento.

26 De doctr. christ. II, 1, 1, PL. 34, 35: Signum est enim res, praeter speciem quam ingerit sensibus, aliud aliquid ex se faciens in cogitationem venire: sicut vestigio viso, transisse animal cujus vestigium est, cogitamus; et fumo viso, ignem subesse cognoscimus..., cfr. últimamente J. ENGELs. "La doctrine du signe chez saint Augustin": Studia Patristica, VI/4 edited by F. L. Cross, Berlín 1962, 366-372.
} 
a un signo cualquiera, sino al signo de una cosa sagrada, como aparece en la Carta a Marcelino ${ }^{27}$.

Los signos, sin embargo, son múltiples y Berti se acerca cada vez más a una definición de sacramento. Para ello ahora distingue una serie de signos:

Signorum quidem aliqua nullam habent cum re quam significant similitudinem, ut campanae sonus signum est convocandi clerum; quaedam similitudinem talem habent, ut absque ulla vel humana vel divina institutione commonstrent rem quam significant, ut vestigium in arena impressum indicat pedem hominis aut alterius animantis; nonnulla denique signa ex institutione rem aliquam indigitant, sed cum ea habent analogiam aliquam et proportionem, ut immolatio Isaac Christi sacrificium, productio Evae institutionem Ecclesiae praefigurarunt..." 28.

Estos últimos le permiten entrar en lo que San Agustín entendería por sacramento y a éstos pertenecería. En este sentido interpretará la Epist. 98 a Bonifacio ${ }^{29}$. Berrouard ha estudiado la similitudo en este mismo pasaje, diciendo al fin que "bajo la presión de Bonifacio (Agustín) debe llevar su análisis más adelante y le aparece que si el sacramento es un signo y un símbolo, es un signo que implica participación a la realidad significada" ${ }^{30}$. Los sacramentos necesitan esa cierta semejanza con la cosa significada, una cierta analogía o proporción, pero habría que preguntarse por la relación entre la proporcionalidad o analogía con la cosa significada y la eficacia de esos signos sagrados.

De aquí era ya fácil pasar a la definición de sacramento o al significado más completo de la palabra y a una descripción concisa. Lo agustiniano podría frenar aquí y sería difícil buscar un modo más preciso de definir el sacramento en San Agustín, aunque puedan recogerse otros elementos, y Berti lo hará en lo sucesivo.

\section{Definición DE SACRAMENTo Y PRUEba agustiniana.}

Para llegar a una conclusión, analiza la historia precedente y las controversias, ateniéndose especialmente al Concilio de Trento. Una vez

27 Epist. 138, 1, 7, PL. 33, 527: Nimis autem longum est convenienter disputare de varietate signorum, quae cum ad res divinas pertinent, Sacramenta appellantur.

28 BERTI, o. c. III, 170.

29 Epist. 98, 9, PL. 33, 364: Si enim sacramenta quamdam similitudinem earum rerum quarum sacramenta sunt, non haberent, omnino sacramenta non essent. Ex hac autem similitudine plerumque etiam ipsarum rerum nomina accipiunt.

30 M. F. Berrouard, 1. c. 293. 
examinado brevemente esto, nos ofrece su definición de sacramento, que se había insinuado ya a través de las proposiciones estudiadas:

Ex quibus omnibus videtur nobis posse Sacramentum hac definitione describi: Sacramentum est invisibilis gratiae signum sensibile, divinitus institutum et Christi nomine sacroque ritu exhibitum, et hominum sanctificationem efficiens 31 .

La primera parte serviría para los sacramentos de la Antigua Ley y la segunda mostraría la diferencia entre los de uno y otro Testamento. Así definido, prueba cada uno de sus miembros sobre todo con la doctrina agustiniana que citará hasta la saciedad. Cuanto haya que aplicar luego a cada uno de los sacramentos penderá de este primer problema, aunque no sea fácil la enumeración de los siete sacramentos en los Padres y en San Agustín. Cuando trate del número de los sacramentos buscará razones valiosas para decir que si no se habla de todos explícitamente, al menos pueden colegirse de las diferentes referencias que se hacen en pasajes variados de sus obras ${ }^{32}$. Entra, pues, a cotejar su definición y a avalarla con los textos de San Agustín. Seguimos sus pasos y las citas que se hacen del Obispo de Hipona.

a) El sacramento es un signo sensible.-El signo, ya sabemos cómo lo definía Agustín - definición que recogía también Berti en otro lugar- ${ }^{33}$ requiere una cierta especie o apariencia que ofrece a los sentidos. A este propósito no recurre ya al De doctrina christiana, sino al De catechizandis rudibus 26, 50, PL. 40, 344-345, donde Agustín escribe:

De sacramento sane (forte, salis) quod accipit, cum ei bene commendatum fuerit, signacula quidem rerum divinarum esse visibilia, sed res ipsas invisibiles in eis honorari; nec sic habendam esse illam speciem benedictione sanctificatam, quemadmodum habetur in usu quolibet: dicendum etiam quid significet et sermo ille quem audivit, quid in illo condiat, cujus illa res similitudinem gerit.

La referencia que le interesaba al presente era "signacula rerum divinarum esse visibilia". Y para probar este miembro de su definición en el que aparece la visibilidad y tangibilidad de los signos, multiplica los textos agustinianos en que se manifiestan los sacramentos como "corporalia

\footnotetext{
3.1 BERTI, o. c. III, 171.

32 ID., o. c. III, 185-188.

33. Cfr, nota 26 .
} 
sacramenta" 34, como "sacramenta visibilia" ${ }^{35}$, como "elementum et visibile verbum" 36, como "sacrosancta signacula" 37. Por fin Berti recurre a otro texto, que usará luego frecuentemente. Está tomado del Contra Faustum XIX, 11, PL. 42, 355. Merece la pena citarlo aquí, porque desempeña un papel capital en este tema:

In nullum autem nomen religionis seu verum seu falsum, coagulari homines possunt, nisi aliquo signaculorum vel sacramentorum visibilium consortio colligentur: quorum sacramentorum vis inenarrabiliter valet plurimum, et ideo contempta sacrilegos facit. Impie quippe contemnitur, sine qua non potest perfici pietas.

La unión visible entre los miembros de una religión exige lazos visibles, que se determinan y manifiestan en los sacramentos. A esto apelará en otro lugar ${ }^{38}$.

b) Es un signo de la gRACia INvisible.-En la misma definición se dice que realiza la santificación del hombre y antes se anuncia que es signo de la gracia invisible. El sacramento es un signo y un signo sensible, pero el signo necesita ser de algo o de alguien, y se especifica diciendo

34 Contra Faustum XIX, 16, PL. 42, 356-357: Quid enim aliud quaeque corporalia sacramenta nisi quaedam quasi verba visibilia, sacrosancta quidem, verumtamen mutabilia et temporalia? El problema que tenía aquí planteado era la diferencia de signo para los sacramentos del Antiguo y del Nuevo Testamento, pero no de significación. La única diferencia sería de tiempo, en cuanto que en aquellos se trataba de una cosa que se cumpliría y en éstos de algo ya cumplido, del faciendum y del factum.

35 Quaest. in Hept. III, q. 84, PL. 34, 712, en que aparece la santificación invisible y la visible, por Dios y por Moisés, esta última interpretada por Berti como santificación legal. La sacramentaria agustiniana insinúa aquí un gravísimo problema, que no podemos abordar al presente.

36 In Joan. Evang. tr. 80, 3, PL. 35, 1.840: Se habla del bautismo y del texto de San Juan: Jam vos mundi estis propter verbum quod locutus sum vobis, al que Agustín agrega: Quare non ait, mundi estis propter Baptismum quo loti estis, sed ait, propter verbum quod locutus sum vobis; nisi quia et in aqua verbum mundat? Detrahe verbum, et quid est aqua nisi aqua? Accedit verbum ad elementum $_{11}$ et fit Sacramentum, etiam ipsum tanquam visibile verbum.

37 Epist. ad Rom. inchoat. expos. 18, PL. 35, 2.101. El contexto de Agustín se refiere al conocimiento de la voluntad de Dios y el pecado contra el Espíritu Santo que sería pecar conocida la voluntad de Dios. $Y$ entonces lo primero que hay que investigar y discutir es cuándo se conoce la voluntad de Dios. Algunos, dirá el Santo, la conocen aun antes de recibir el bautismo, como sucedió a Cornelio, no sin haber sido instruído por San Pedro y haberle manifestado con signos clarísimos el Espíritu Santo cuál era esa voluntad. Sin embargo no por eso despreció el sacramento, antes bien lo recibió conocido. Agustín añade: quanquam non ideo Sacramenta illa contempserit, sed multo certius baptizatus sit; ut etiam ipsa sacrosancta signacula, quorum res in eo praecesserat, ad perficiendam scientiam veritatis percipere nullo modo moraretur (Act 10). Multi autem nec post acceptum Baptismum curant cognoscere voluntatem Dei.

38 Cfr. el apartado ¿Cuándo comenzaron los sacramentos? 
que es signo de la gracia invisible. La prueba la busca en un texto agustiniano, que cita:

Nam sine ista sanctificatione invisibilis gratiae, visibilia sacramenta quid prosunt? Merito enim quaeritur, utrum etiam ista invisibilis sanctificatio sine visibilibus sacramentis, quibus visibiliter homo sanctificatur, pariter nihil prosit: quod utique absurdum est 39 .

No se da, empero, al parecer, relación de causalidad entre los sacramentos visibles y la santificación invisible, pues se decía en precedencia en el mismo texto, hablando de Dios y de Moisés que santifican:

Quomodo ergo et Moyses sanctificat et Dominus? Non enim Moyses pro Domino: sed Moyses visibilibus sacramentis per ministerium suum; Dominus autem invisibili gratia per Spiritum sanctum, ubi est totus fructus etiam visibilium sacramentorum...

Berti interpreta esa santificación de los sacramentos de la Antigua Ley como una santificación legal, es decir, era una santidad umbrática, figura de la santificación que había de conferirse por medio de Cristo.

Aquí se planteaba, como era natural, la diferencia entre los sacramentos de la Ley Antigua y los de la Nueva. Berti, insistiendo en ese texto de San Agustín, dirá que son iguales in re significata, ya que significan el mismo Cristo y su gracia ${ }^{40}$. La diferencia entre ambos será preciso buscarla en que los sacramentos de la Antigua Ley eran signo del Cristo por venir, y los de la Nueva son signo de la redención ya realizada. Y se aduce aquí Contra Faustum XIX, 14-15, PL. 42, 355$356^{41}$. Ante la diversidad de gracias, que él se empeña en distinguir con Santo Tomás y en parte siguiendo el Agustín de Contra Faustum XIX, 13, PL. 42, 355, en "gracia presente, que adorna y santifica al alma, como la justicia, la remisión de los pecados, algunos otros dones de Dios que colma a quien recibe dignamente los sacramentos, luego

39 Quast. in Hept. III, q. 84, PL. 34, 712.

40. BERTI, o. c. III, 171.

41 Contra Faustum XIX, 13-14-15, PL. 42, 355-356. El sentido general del Antiguo Testamento figura del Nuevo $y$ el Nuevo figura de lo escatológico se manifiesta claramente en este pasaje, digno de ser notado: Proinde prima sacramenta, quae observabantur et celebrabantur ex Lege, praenuntiativa erant Christi venturi: quae cum suo adventu Christus implevisset, ablata sunt; et ideo ablata, quia impleta; non enim venit solvere Legem, sed adimplere: et alia sunt instituta virtute majora, utilitate meliora, actu faciliora, numero pauciora, tanquam justitia fiedei revelata, et in libertatem vocatis filiis Dei jugo servitutis ablato (Galat 5, 1-13), quod duro et carni dedito populo congruebat (cap. 13). Y prosigue en los dos siguientes exponiendo estos pensamientos de modo extraordinario. 
la gracia recibida de la Encarnación del Señor, de la pasión, redención y resurrección, y si hablamos de los sacramentos antiguos, la alianza pactada, la promesa de Dios y la liberación de la servidumbre, y por fin la gracia futura, a saber la gloria y la consecución de la vida eterna", los sacramentos serán adjetivados distintamente según sean signos de una gracia o de otra. Así nos hallaremos frente a los sacramentos demostrativos de la gracia presente, conmemorativos de la gracia pasada a prenunciativos de la futura ${ }^{42}$.

Pero hay algo más que Berti pone aquí de manifiesto y que continúa la línea agustiniana en una teoría cara a San Agustín. Los sacramentos son todo eso, pero a su vez son "commonitoria" del propio deber y de la realización de lo significado. He aquí el sentido personalista de la sacramentaria que no es automática, simplemente por esa palabra que alguien ha calificado de bárbara, ex opere operato, sino que exige e impone la responsabilidad personal. Así recuerda nuestro autor que la circuncisión advierte —admonet - que cada cual circuncide su corazón y la inmolación de víctimas, que se tema la suprema potestad de Dios, al igual que ahora el bautismo nos hace reparar -commonet - en que el hombre viejo ha sido crucificado a una con Cristo, en que se destruya el cuerpo de pecado y no lo sirvamos más, y por la conmemoración del cuerpo de Cristo somos excitados a dar gracias por la redención recibida, y a fomentar entre nosotros que participamos de un solo pan la caridad mutua y el amor ${ }^{43}$. De esta suerte el sacramento adquiere toda su virtualidad y de su aparente automatismo se trueca en mucho más personal, no sólo en la preparación requerida, sino también en la participación directa con la consciencia y la reflexión humana en el acto de la aceptación y confección.

c) Es un SIgNo DIVINAMENTE INSTITUído.-A partir del efecto espiritual que produce y significa, se asciende a la fuente y a la raíz divina del mismo, pero se atiene también aquí a una palabra de Agustín, que toma al pie de la letra, en la que se dice que el "sacramentum est utile signum divinitus institutum" ${ }^{44}$. Sin embargo Agustín no trataba, al usar

42 BERTI, o. c. III, 171.

43 ID., Ibid.

44 De doctr. christ. III, 9, 13, PL. 34, 70-71: Sub signo enim servit qui operatur aut veneratur aliquam rem significatam, nesciens quid significet: qui vero aut operatur, aut veneratur utile signum divinitus institutum, cujus vim significationemque intelligit, non hoc veneratur quod videtur et transit, sed illud potius quo talia cuncta referenda sunt. 
esa expresión, sólo del signo sacramental, pues reclama a otros muchos signos útiles. Hace referencia a lo que había dicho hablando de los signos que comportan una semejanza con la cosa significada. Esto es necesario verlo con claridad, porque institucionalmente le da la significación. En la ley de naturaleza podrá decir que falta este elemento, pero el hombre ha tenido sacramentos que se ha constituído instinctu interiori, como veremos.

d) Y administrado en nombre de Cristo.-La cualidad del sactamento la contradistingue esta condicional, de suerte que aquí se esclarece la doctrina ya en la misma definición. Cita Jo 1, 13 y I Cor 1 para remitirnos luego al lugar tan conocido de Agustín In Joan. Evang. tr. 6, 6.7.8, PL. 35, 1.427-1.429 45. Berti hace entrar este elemento en la definición de sacramento en plena concordancia con San Agustín, que se explica en la controversia donatista de modo especial.

\section{¿CUÁNDO COMENZARON A EXISTIR LOS SACRAMENTOS?}

Hablando de la institución divina de los sacramentos, nos había insinuado que ampliaría la doctrina más adelante. $\mathrm{Y}$ ahora se hace la pregunta: ¿cuándo comenzaron los sacramentos? Habida cuenta de la definición y de la esencia de los sacramentos,y de la diferencia entre los sacramentos de la Antigua Ley y los de la Nueva, admite, por una parte, de acuerdo con todos los teólogos, exceptuados los herejes que piensan que el hombre es movido sólo internamente y que no necesita de signos sensibles, que en la nueva alianza son necesarios los signos y por tanto los sacramentos. ¿Lo eran también antes de Cristo, en la Ley Antigua? Berti distingue tres momentos o estadios y en cada uno de ellos admitirá sacramentos, bien que existan opiniones en contrario. Esos tres estadios son los siguientes, con sus explicaciones:

a) El estado DE inocencia.-Muchos escolásticos y teólogos han negado que en el estado de inocencia se dieran sacramentos, considerada la esencia de éstos y sus efectos. Berti expone esa opinión con sus razones y luego pasa a explorar la sentencia de aquellos que piensan que en el

45 En el texto que usamos se remite al Tract. IX, pero a juzgar por el contexto se refiere al conocido paso que hemos señalado en el texto. 
estado de inocencia habría también sacramentos. Esta segunda opinión la defendían algunos agustinos, siguiendo a $F$. Bellelli, que argumentaba con testimonios de San Agustín ${ }^{46}$. Berti responde también a estos argumentos.

Entre las pruebas aducidas para probar la existencia de sacramentos en el estado de inocencia se lee el texto famoso del Contra Faustum XIX, 11, PL. 42, 355. Berti, buscando el equilibrio en la interpretación agustiniana, dice que Agustín en este lugar o habla de misterios y ritos, por los que se distingue una religión de otra, o al menos no se refiere al estado de inocencia. Las dos cosas las repliega con un análisis preciso del texto ${ }^{47}$. Una segunda razón, a que apelaban los agustinianos era otro texto del De Gen. ad litt. VIII, 4, 8, PL. 34, 375, en el que lignum vitae viene considerado como "sacramentum" ${ }^{8}$, y más adelante, en VIII, 5, 10, PL. 34, 376, la sabiduría venía señalada por medio del lignum, es decir, de una criatura corporal, como por una especie de sacramento $\rightarrow$ tanquam sacramento quodlam significari- ${ }^{49}$, $y$ ese mismo árbol mantenía la salud estable del hombre ${ }^{50}$. Responde también a estas interpretaciones de los textos agustianos recordando que se emplea en ellos la palabra "sacramentum" en sentido amplio, en el que significa res arcana, y lo prueba con el contexto, deshaciendo uno a uno los argumentos que, estribando en Agustín, recogían a su favor, aludiendo al ejemplo del matrimonio del que se habla también allí y que era sacramento, pero sólo en sentido amplio.

A pesar de que no sigue la interpretación de San Agustín dada por los autores de su misma sentencia, sino que prefiere la fidelidad al texto,

46 Las palabras de BerTI, o. c. III, 172 son éstas: Quidam censent etiam in statu innocentiae quaedam sacramenta exstitisse: quam opinionem amplectuntur nonnulli Ordinis nostri Scriptores cum Fulgentio Bellelli lib. I Mentis Aug. cap. 20 his argumentis innixi. En efecto Bellelli, Mens Augustini de statu creaturae rationalis ante peccatum. Lucernae 1711, dedica el cap. 29 del lib. I a este punto: Expenditur ex Augustino an in innocentiae statu potuerit esse, vel reapse fuerit aliquod vere dictum Sacramentum? Los argumentos aducidos de Agustín son los que vemos aquí examinados por Berti. Las páginas dedicadas son 136-144, dando por supuesto desde el principio que en general los escolásticos excluyen los sacramentos del estado de inocencia. El capítulo 20 citado en el texto que usamos de Berti está sin duda alguna equivocado.

47 BERTI, o. c. III, 173.

48 Dice así el texto: Nec sine mysteriis rerum spiritualium corporaliter praesentatis voluit hominem Deus in paradiso vivere. Erat ei ergo in lignis ceteris alimentum, in illo autem Sacramentum.

49: ...per lignum id est per corpoream creaturam tanquam Sacramento quodam significari Sapientiam in paradiso corporali, Sapientiam utique qua recte vivimus...

50 De Gen. ad litt. VIII, 5, 11, PL. 34, 377. 
aprueba esa opinión y da razones al margen de los textos del Santo, aunque con pensamiento que le delata plenamente. Esas razones en favor de la existencia de sacramentos en el estado de inocencia, pueden concretarse en las siguientes: el del hombre y su composición, recurriendo aquí en general a Agustín con este motivo, "propterea quod homo corpore animoque conflatus per corporalia signa potest in quocumque statu devenire in cognitionem rerum spiritualium, ut non obscure docet citato loco Augustinus, ipsaque ratio demonstrat". Es un principio básico en todo el agustinismo, éste de visibilibus ad invisibilia, de corporalibus ad incorporalia. La teoría de la admonición tiene aplicación en todos los estados.

Además de esto, pasando a la gracia, agrega que por esos signos puede conferirse no una gracia sanante, que no sería necesaria allí sino una gracia que fomentase y aumentase la primera. Habría sacrificios también, ya que la criatura racional se compone de alma y cuerpo y tiene que adorar y servir a Dios con todo lo que es, con actos externos e internos. Añade que los hombres visibles constituirían una Iglesia visible que necesitaría de signos visibles para unirse. No existirían allí los sacramentos futuros, que tienen la virtud de conferir la gracia intuitu meritorum Christi, o instituídos para la remisión de los pecados, porque, según nuestra opinión —dice Berti- Cristo no hubiese venido, si Adán no hubiese pecado, y no son los sanos los que tienen necesidad de médico, sino los enfermos ${ }^{51}$. Berti reconoce que no es único en defender esta sentencia y no ve, por su parte, repugnancia en que existieran en ese primer estadio sacramentos.

b) En el estado de naturaleza.-Es decir, desde la caída de Adán hasta la ley dada por Dios a Moisés ${ }^{52}$. En este estadio distingue los párvulos de los adultos, admitiendo luego la existencia de sacramentos, de algún signo de la gracia, para los párvulos. El fundamento lo halla en San Agustín, que afirma que no puede negarse que antes de la circuncisión tuvieran los siervos de Dios un remedio que ofrecer a los niños, aunque se ignore cuál era ese ${ }^{53}$. Además, piensa que la razón está de

51 BERTI, O. c. III, 173.

52 ID., 174.

53 Contra Julian. V, 11, 45, PL. 44, 809-810: Nec ideo tamen credendum est, et ante datam circumcisionem famulos Dei, quando quidem inerat eis Mediatoris fides in carne venturi, nullo sacramento ejus opitulatos fuisse parvulis suis, quamvis quid illud esset aliqua necessaria causa Scriptura latere voluerit. 
su parte, ya que si siempre fue necesaria la fe en Cristo para la salvación, y los niños no pueden actualizar esa fe y mediante ella la justificación, era necesario algún remedio ${ }^{54}$.

Algunos opinan con Santo Tomás que bastaba entonces la fe sola sin manifestación alguna por signos externos, pero Berti, con textos de Agustín, dice que no es suficiente, sino que aunque nos sea desconocido el signo sensible, antes de Abraham existía ${ }^{55}$. Los sacramentos significaban todos, como ha insinuado con el Contra Faustum XIX, 16, la misma realidad, es decir, Cristo y su gracia, y en cada uno de los estadios se lograban aquellos sacramentos que convenían a ese estado. En la ley escrita se determinaron, pero en la ley de naturaleza, como los hombres eran movidos solamente por el instinto interior a adorar a Dios, por ese mismo instinto, sin ninguna ley externamente dada, determinaban los signos sensibles que usarían en el culto de Dios y para expiar los pecados ${ }^{56}$.

La existencia de esos sacramentos también para los adultos la prueba por los sacrificios, por el culto exterior, por la forma visible de religión. Se ignora cuáles eran esos sacramentos, pero existían. La institución procedía del instinto divino que los inspiraba ${ }^{57}$. Dejamos aquí este punto en compás de espera.

c) La circuncisión.-Era el tercer estadio del proceso que examinaba Berti en la institución de los sacramentos. Al tema le dedica muchas páginas ${ }^{58}$. Lo trata bajo este epígrafe:

Agitur de origine circumcisionis et quaeritur an fuerit Sacramentum divinitus institutum ad delendum originale peccatum $\mathbf{5 9}$.

No nos interesa el examen que hace de fuentes en los textos escriturísticos originales y aún en autores paganos. Nuestra mirada, como en lo precedente, se flecha a San Agustín, que sobresale de modo particular en este tema. Las proposiciones se encadenan en plan escolar y luego de decir que la circuncisión no ha sido instituída sólo para

54 Se cita también aquí De nupt. et concupisc. II, 11, 24, PL. 44, 449-450.

55 Ese desconocimiento viene señalado en el texto de las notas precedentes $y$ en De peccato originali II, 30, 35, PL. 44, 402.

56 BERTI, o. c. III, 174.

57 ID., 175.

68 ID., 175-178.

59. ID., 175 . 
distinguir a los hijos de Abraham de los gentiles ${ }^{60}$, pasa a considerarla como "un signum commonens ut carnis voluptates frenentur, iccirco in illa parte corporis impressum, quae vehementius titillat, ut inquiunt citatis in locis Augustinus et Thomas". Y pasando revista a testimonios de la Escritura, de Filón y de San Cipriano, busca apoyo en Agustín para expresar que la circuncisión significa el despojo y el sepelio de las concupiscencias carnales ${ }^{61}$.

Este significado simple conduce directamente a otro más profundo, que se insinuaba ya en alguno de los textos estudiados por el teólogo agustino, a saber:

Ad haec circumcisionem fuisse signum baptismatis, regenerationis et etiam immortalitatis praenuntiativum : non uno in loco demonstrat sapientissimus Augustinus 62.

Los textos de Agustín proceden del Contra Julianum VI, 7, 18, PL. 44, 833, y De anima et ejus origine II, 11, 15 PL. 44, 504, en que hablando de las oraciones o del sacrificio ofrecido por los no incorporados a Cristo, se apela al sacrificio de los macabeos que pensaban ofrecido por los no circuncidados, y agrega:

Ita istud dicit, quasi pro incircumcisis illa oblata legerit sacrificia, sicut haec nostra pro non baptizatis censuit offerenda. Circumcisio quippe fuit illius temporis sacramentum, quod praefigurabat nostri temporis Baptismum.

Siendo tan claro el pensamiento de San Agustín a este respecto, cierra el paso a quienes pensaban que era una invención de Agustín y recoge testimonios de los Padres, en especial de San Basilio y de San Ambrosio para decir que "la sentencia que afirma que la circuncisión fue instituída para borrar el pecado original, no fue primeramente excogitada por San Agustín" ${ }^{63}$.

60 ID., 177.

61 In Joan. Evang. tr. 30, 5, PL. 35, 1.634; cfr. también De nupt. et concupisc. II, 11, 24, PL. 44, 450: Ex quo enim instituta est circumcisio in populo Dei, quod erat tunc signaculum justitiae fidei (Rom 4,25, 11), ita ad significationem purgationis valebat et in parvulis originalis veterisque peccati, sicut et Baptismus ex illo valere coepit ad innovationem hominis, ex quo est institutus; además Contra Faustum XVI, 29, PL. 42, 335: Quid enim significat circumcisio carnis? Quid, nisi exspoliationem mortalitatis, quam carnali generatione portamus?

62 BeRTI, O. c. III, 178.

63. ID., ibid. Berti aquí asigna a San Basilio, Hom. 13 sobre el bautismo un texto que Agustín decía ser dẹ Jưan Crisóstọomo en Contra Julian. II, 6, 18, PL. 44, 685-686, 
La proposición $\mathrm{V}$ suena así:

Quod circumcisio sit a Deo instituta ad delendum originale peccatum est expressa sententia Augustini, valide sacris litteris confirmata, et recepta a posterioribus Patribus, et Scholasticis illustrioribus 64 .

En la prueba, los textos de San Agustín se multiplicaban ${ }^{65}$, al igual que en lo sucesivo, ya que tiene que resolver una serie de objeciones que se le hacen. Sin embargo, su tarea estaba cumplida en este aspecto, y aun en el análisis filológico del hebreo se admirará de la agudeza de ingenio de Agustín, quien no entendía el hebreo, pero intuía los textos ${ }^{66}$.

\section{ConcLustones.}

En cualquier tema que entremos a estudiar en nuestro autor recogemos siempire la misma sensación de plenitud y de madurez, de conocimiento y de paciencia. Se desenvuelve con soltura y no está ligado a ninguna tendencia en la solución de los problemas teológicos que se plantean. Es libre bajo la égida de San Agustín.

a) Berti maneja con profusión y profundidad en la sacramentaria los textos de San Agustín y ha captado bien su pensamiento.

b) La interpretación que ofrece sobire los diferentes significados de la palabra y el empleo que ha hecho del Santo está en línea con los más recientes estudios modernos, si bien los textos examinados no han sido todos, y ha insistido más en lo teológico que en lo filológico.

c) Su definición de sacramento tiene una base agustiniana, y los elementos que la componen hallan en el Obispo de Hipona una confirmación. Sin embargo es necesario convenir en que a San Agustín le faltaba todavía claridad para precisar un único sentido de sacramento.

d) En lo referente a los sacramentos en los diversos estados continúa la línea agustiniana e interpreta la diferencia entre los sacramentos de la

64 Berti, o. c. III, 179.

65 Los textos de San Agustín son los siguientes, citados por su orden e interpretados en estas páginas por Berti, Epist. 187, 11, 34, PI. 33. 745; Contra Julian. III, 18, 34, PL. 44, 719-720; De nupt. et concupisc. II, 11, 24. PL. 44, 449-450; De peccato originali II. 30, 35. PL. 44, 402; Op. imp. contra Julian. II, 201, PL. 45, 1.227; De civ. Dei XVI, 27, PL. 41, 506-507; Contra litt. Petil. II, 72, 162, PL. 43, 309; De bapt. IV, 24, 31, PL. 43, 174-175; Quaest. in Hept. II. q. 11, PL. 34, 599-600, etc. Textos examinados por Berti, en las pp. 179-180.

66 At Augustinus, quamvis linguae hebraicae vim non attenderit, hanc ta. men responsionem, tanta erat ingenii eius acies, tanta in scripturis enodandis libratio, adhibuit loco nuper laudato (BERTI, o. c., III, 181). 
Antigua y de la Nueva Ley, como santificación legal en aquellos. Habría que decir que es uno de los puntos difíciles en la interpretación de San Agustín. Para solucionar este tema general sería necesario profundizar en la circuncisión como signo divinamente instituído para borrar el pecado original. Berti lo ha abordado ampliamente, defendiendo la tesis agustiniana, que espera todavía un estudio más detallado, fundamental por otra parte en la controversia pelagina.

P. José MoRÁN, O. S. A. 